\title{
The secondary work embrittlement in sheet steels
}

\author{
Daoming Li, Götz Heßling and Wolfgang Bleck
}

Increasing requirements for cold forming properties have led to the development of interstitial free (IF) steels. The excellent deep drawability of IF steels results from extra low carbon and nitrogen contents $(<50 \mathrm{ppm})$ in addition to titanium and niobium microalloying for stabilising the interstitial elements. After cold work, a secondary operation may lead to embrittlement, often via intergranular fracture. This so called secondary work embrittlement phenomenon has been analysed using several methods, of which the deep drawing of cups as primary work is the most common method. The influence of impurities on grain boundaries is observed by means of surface analytic tools, e.g. by Auger electron spectroscopy. The main influence is mechanically the primary work and the kind of secondary loading. From the metallurgical viewpoint, grain boundary weakening elements, especially phosphorus, and grain boundary strengthening elements, e.g. Boron and free carbon, have a strong effect on secondary work embrittlement.

Verformungsinduzierte Versprödung von IF Stählen. Steigende Anforderungen an die Kaltumformbarkeit von Tiefziehstählen führten zur Entwicklung von Stählen ohne interstitiell eingelagerte Atome (IF-Stähle). Deren herausragende Tiefzieheigenschaften resultieren aus der Einstellung niedrigster Kohlenstoff- und Stickstoffgehalte $(<50 \mathrm{ppm})$ in Verbindung mit Mikrolegierungsgehalten an Titan und Niob, die eine stabile Abbindung der interstitiellen Atome gewährleisten. Nach einer Kaltumformung versagen IF Stähle bei weiterer Beanspruchung häufig spröde, meist in Verbindung mit Korngrenzenbruch. Zur Analyse dieses Effektes wurden verschiedene Methoden entwikkelt, wobei die Verwendung von tiefgezogenen Näpfchen als Erstumformung am weitesten verbreitet ist. Der Einfluß einzelner Elemente auf die Korngrenzen wird mit oberflächenanalytischen Methoden, wie zum Beispiel der Auger-Spektroskopie, untersucht. Als Haupteinflußgrößen zeigen sich verfahrenstechnisch die Vorverformungsgeschichte und die Belastungsweise bei der zweiten Verformung. Legierungstechnisch haben korngrenzenversprödende Elemente, insbesondere Phosphor, und korngrenzenfestigende Elemente, zum Beispiel Bor und ungebundener Kohlenstoff, starken Einfluß auf die verformungsinduzierte Versprödung.

In order to meet the demands of the automobile industry, several grades of interstitial free (IF) steels have been developed in recent years [1], due to the fact that nonmicroalloyed Al-killed steels are not suitable for obtaining excellent deep drawability and non-aging properties during short time annealing. IF steels are ultra low carbon steels (ULC-steels), usually containing less than $50 \mathrm{ppm} \mathrm{C}$ and $\mathrm{N}$, respectively, achieved through vacuum degassing, in which carbonitride forming elements, such as $\mathrm{Ti}$ and $\mathrm{Nb}$, are added to stabilise, the remaining $\mathrm{C}$ and $\mathrm{N}$ contents. Due to their low yield strength and high $r$ values, IF steels are superior, in formability terms, to aluminium killed steels particularly when continuous annealing including hot dip coating processes are employed. Moreover, by suitable chemical modifications, higher strength IF steels with good formability can be produced.

However, IF steels may exhibit embrittlement, often via intergranular fracture (IGF), which occurs during a secondary operation after a primary forming stage involving the generation of large compressive circumferential stresses, e.g. forming by deep drawing. Low temperature and impact loading tend to intensify the embrittlement. The phenomenon is called secondary work embrittlement (SWE) or cold work embrittlement (CWE) or strain-induced embrittlement [2]. The term SWE is used throughout the present paper. Although SWE is prominent in IF steels, similar embrittlement has also been reported in rephosphorised low carbon steel [3]. The brittle fracture in the case of SWE is typically characterised by IGF, as is exem- plified in figure 1. Generally, the fracture is initiated intergranularly and propagates intergranularly and/or transgranularly [4]. The most common criteria for the susceptibility to SWE is the ductile to brittle transition temperature (DBTT). Above this temperature no embrittlement by SWE is observed. The proportion of IGF usually increases with increasing the grain boundary concentration of harmful elements such as $\mathrm{P}[5 ; 6]$ or with decreasing that of deembrittling elements like B [7] and C [5]. As a steel tends to fracture more favourably in the intergranular mode, the corresponding DBTT also increases.

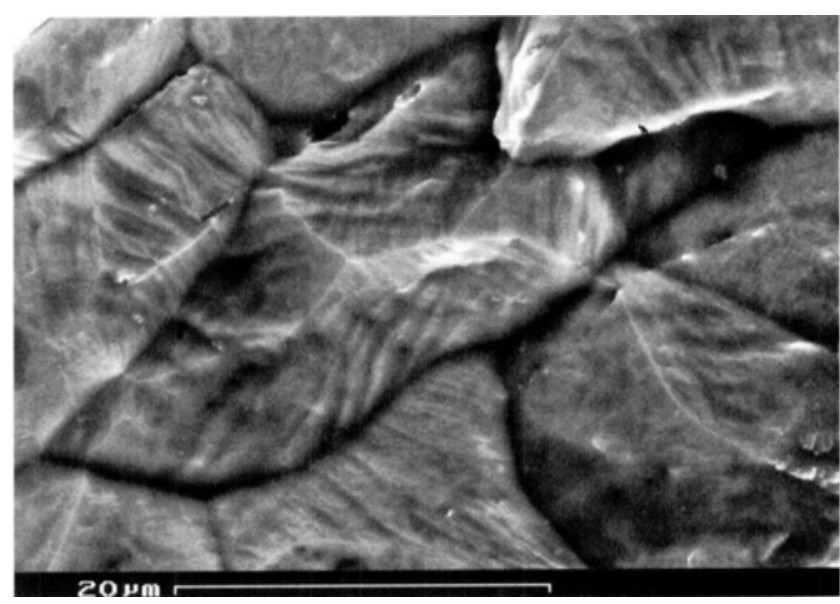

Figure 1. SEM fractograph of an IF steel failed in the cup test, showing intergranular fracture

Dr.-Ing. Daoming Li, (now with University of Michigan, USA); Dipl.-Ing. Görz Heßling: Professor Dr.-Ing. Wolfgang Bleck. Institut für Eisenhüttenkunde, RWTH Aachen, Germany. 


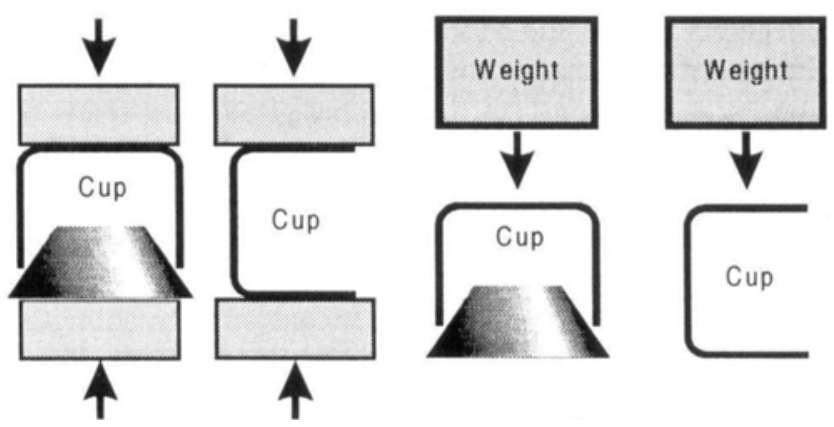

Figure 2. Typical loading modes of the cup tests for evaluating SWE

At present, in-service failure of IF steels has scarcely been reported to be attributed to SWE. Nevertheless, the susceptibility of steels to SWE is being paid special attention because new formable steel grades are increasingly required, especially high strength IF steels to which $P$ is usually added to maintain good drawability. Furthermore, recycling scrap may cause an increase of tramp elements in steels in years to come. Therefore, extended investigations on IGF and/or SWE are justified from both academical and industrial viewpoints.

In the present paper, a review on the literature related to SWE in sheet steels is given, some important parameters are dicussed and approaches for further studies are proposed.

\section{Approaches to evaluate SWE}

Mechanical testing. To date various experimental methods have been developed to evaluate the susceptibility of SWE. The differences between the test methods are

- primary work for specimen preparation: specimens can be conical cups, flat cups, deep drawn production parts or 0t-bend-stripes;

- secondary work which is applied during testing: this can be cup expansion by a conical punch, side crush of cups or reverse bend of stripes;

- edge conditions: as-drawn or trimmed;

- loading mode: impact or static;

- evaluation criteria: DBTT, crack-length, critical strain, pass/fail, absorbed energy, type of fracture or failure load.

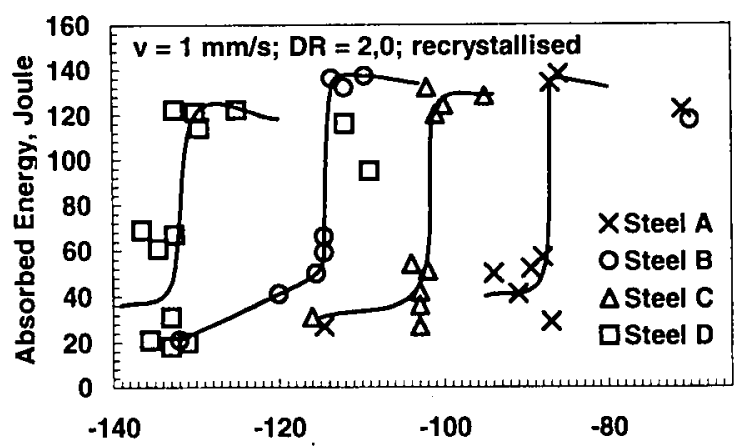

Figure 3. Absorbed energy as a function of temperature in the instrumentated cup test ( $v$ - loading speed, DR - draw ratio); the DBTT is determined to $-102{ }^{\circ} \mathrm{C}$

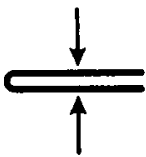

(a)

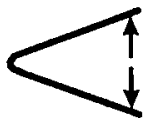

(b)

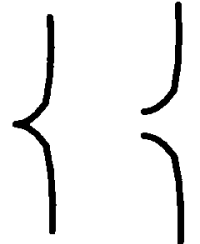

(c)
Figure 4. Schematic illustrations showing key steps constituting the bend-unbend test of stripes used to evaluate the SWE

The possibility of combining these different test conditions led to a multitude of different testing techniques as referred to in [4]. That is why it is difficult to compare the results of various investigators. Figure 2 shows schematically the loading differences for the often used cup tests.

An improved test method used by the present investigators is an instrumentated cup test which is carried out in a high speed tensile testing machine, allowing loading speeds up to $5000 \mathrm{~mm} / \mathrm{s}$. A cooling chamber, working with liquid nitrogen, is installed on the loading fixture of the test machine, with which the cup is expanded with a conical punch in-situ at a specified temperature, eliminating the temperature rise due to moving the specimen from the cooling facility to the testing equipment as in most conventional cup tests. Furthermore, the temperature increase during forming (e.g. by a non-cooled conus) is minimized because of the cooling of the whole test environment. The absorbed energy is calculated from the load-displacement curve. One obvious advantage of this improved test method is that the transition region for DBTT is abrupt, as shown in figure 3 for a $\mathrm{Ti} / \mathrm{Nb}$-IF steel, and hence the DBTT can be determined unambigously.

Considering that the cup test requires special cupmaking equipment and testing facilities and is time consuming, a bend-unbend test has been introduced [8], figure 4. The method consists of the following steps: a) bending strips (usually with an inner radius of 0 ) as primary work; b) cooling down the bend specimen to a specified temperature and unbending the specimen as secondary work; c) deciding whether the specimen passes or fails. The DBTT is defined as the lowest temperature for passing the test. Further investigations of this method clarified the mechanical conditions (such as the strain distribution around the bend tip) inducing the embrittlement and correlating the bend-unbend test results with the cup test results [9].

Chemical/thermodynamical approaches. Chemical examination is aimed to investigate which elements affect the grain boundary properties and with which intensity.

Auger electron spectroscopy (AES) is a much used tool for studying the segregation of impurities to grain boundaries [10]. In the case of examining IGF, AES allows to identify and to calculate the concentration of segregants. The IGF surfaces have to be produced in-situ in the ultra high vacuum in order to avoid influences of the atmosphere. In addition low energy electron diffraction (LEED) allows to determine the structure of surfaces [11].

The thermodynamics of segregation are described by the Langmuir-McLean equation [12]: 


$$
\frac{\theta_{i}}{1-\theta_{i}}=x_{i} \exp \left(\frac{-\Delta G_{i}^{0}}{R T}\right)
$$

$\theta_{i}$ : occupancy of grain boundary sites by the segregating element $i, x_{i}$ : mole fraction in the bulk, $R$ : general gas constant, $T$ : temperature, $\Delta G_{i}^{0}$ (usually with a negative value): free energy of segregation.

$\Delta G_{i}^{0}$ is determined by:

$$
\Delta G_{i}^{0}=\Delta H_{i}^{0}-T \Delta S_{i}^{x s}
$$

$\Delta H_{i}^{0}$ : enthalpy of segregation, $\Delta S_{i}^{x s}$ : excess entropy of segregation.

Table 1 lists some typical values of the free energy obtained in different alloying systems regarding the segregation by a particular element. A general trend is found in table 1: either $B$ or $C$ has a free energy value significantly lower than that of $P$ regarding their segregation to grain boundary. This general observation rightly accounts for the strengthening effects of $B$ and $C$ segregation to the grain boundary.

Equation (1) predicts that the segregation increases with decreasing temperature and with increasing bulk concentration. This was verified experimentally: lowering the annealing temperature from 800 to $500{ }^{\circ} \mathrm{C}$ for a $\mathrm{Fe}-\mathrm{P}$ alloy with $0.17 \% \mathrm{P}$ bulk concentration increases the grain boundary concentration of $P$ about $40 \%$. Raising the $P$ bulk concentration from 0.018 to $0.046 \%$ at an annealing temperature of $600{ }^{\circ} \mathrm{C}$ increases the grain boundary concentration of $P$ the same [12].

By comparing technical segregation with such equilibrium experiments it has to be considered that the segregating elements have to reach the grain boundary by diffusion. As the influence of temperature on the diffusion is reverse to the influence on the segregation, the temperature range $400-600{ }^{\circ} \mathrm{C}$ is critical for $\mathrm{P}$ segregation [12]. This competitional sensitivity to temperature of segregation and diffusion is further confirmed by recent investigation [15], in which maximum enrichment of $P$ is achieved for the temperature range between 600 and $780^{\circ} \mathrm{C}$ for $\mathrm{Ti}-\mathrm{Nb}$ IF steels with $\mathrm{P}$ addition and with $\mathrm{Mn}$ adddition by an annealing time of 5 minutes. This temperature range is, in comparison to the former, relatively high as a nonequilibrium segregation is focused.

\section{Mechanisms of IGF/SWE in IF steels}

Chemical/metallurgical viewpoints. Impurities in steels can have strong effects on the mechanical behaviour, especially when they tend to enrich or segregate at grain boundaries. As a general rule, elements of groups IV to VI in the periodic table, e.g. Sn, P, As, Sb, S, $\mathrm{Se}$ and $\mathrm{Te}$ segregate at grain boundaries and cause the embrittlement of steels [12]. Solutes of a low solubility different steels segregate strongly and vice versa [10]. Intergranular embrittlement of steels at low temperatures correlates with impurity segregation [16]. In iron-based alloy systems, Si [17], P [5], S [18], Ge, As, Se [17], Sn [19], Sb [16], Te, $\mathrm{Bi}$ [17] are identified as embrittlers, while B [20] and C [5] are documented to strengthen grain boundaries.

The weakening effect on grain boundaries can be explained using an embedded atom theory and the strengthening effect using a covalent theory [21...23]. Elements like $\mathrm{B}, \mathrm{C}$ and $\mathrm{N}$ tend to increase grain boundary cohesion and other elements like $\mathrm{H}$ and $\mathrm{O}$ tend to decrease the cohesion, as the first show predominantly covalent binding, which increases the grain boundary strength while the latter have a grain boundary state similar to the chemisorbed state, allowing them to change the state in the time while a crack is passing. Furthermore, a theory of pair bonding has been proposed which enables the change in grain boundary cohesion to be calculated readily from tabulated thermodynamic data of sublimitation enthalpies and atom sizes [24]. For the ferrous matrix, it is indicated by this theory that $\mathrm{Bi}, \mathrm{S}, \mathrm{Sb}, \mathrm{Se}, \mathrm{Sn}$ and $\mathrm{Te}$ will be highly embrittling, followed in order of reducing effect, by $\mathrm{P}$, As, $\mathrm{Ge}, \mathrm{Si}$ and $\mathrm{Cu}$. In increasing order of their remedial effect on embrittlement in iron are N, B and C. For IF steels, the effects of C, B and P on IGF/SWE are of crucial importance and are separately addressed below.

Effect of carbon. It is generally recognised that the lack of solute $\mathrm{C}$ in IF steels significantly decreases the cohesive strength of a grain boundary which is depleted through the stabilisation process by $\mathrm{Ti}$ and/or $\mathrm{Nb}$. Three hypotheses have been proposed to explain the effect of carbon on the IGF [5]:

- site competition hypothesis: $C$ atoms replace segregated $P$ atoms at grain boundaries which leads to a decreased $P$ segregation and thus reduces IGF. Investigations of $\mathrm{P}$ and $\mathrm{C}$ segregation in Fe-P-C alloys show that the segregation of $\mathrm{P}$ decreases with increasing $\mathrm{C}$ bulk concentration $[6 ; 25]$;

- chemical interaction hypothesis: $C$ atoms change the state of the atomic bond around $\mathrm{P}$ and thereby reduce the negative effect of $P$ on the grain boundary cohesion;

- carbon increasing the grain boundary cohesion by itself, irrespective of the $P$ segregation: the grain boundary strengthening effect of $\mathrm{C}$ as described above reduces IGF independent of the $\mathrm{P}$ grain boundary coverage. Ageing at $872 \mathrm{~K}$ for specimens with $0.52 \% \mathrm{P}$ and $0.0008 \% \mathrm{C}$ increases the degree of $\mathrm{C}$ segregation at grain boundaries and lowers the DBTT, while it does not affect the degree of grain boundary segregation of $P$ [5]. There are also examples in other alloying sys-

Table 1. Typical values of free energy $\Delta G_{i}^{0}$ ( $i=$ element) for segregation of $P, C$ and $B$ in

\begin{tabular}{|l|l|l|l|l|l|}
\hline Steel system & $\Delta G_{\mathrm{P}}^{0}$ & $\Delta G_{\mathrm{C}}^{0}$ & $\Delta G_{\mathrm{B}}^{0}$ & microstructure & temperature \\
\hline Fe-10\%Mn-P-B [13] & $-47 \mathrm{~kJ} / \mathrm{mol}$ & & $-97 \mathrm{~kJ} / \mathrm{mol}$ & austenite & $750-1100^{\circ} \mathrm{C}$ \\
Fe-0.2\% P-B [14] & & $-100 \mathrm{~kJ} / \mathrm{mol}$ & $\begin{array}{l}7 \mathrm{f} r i t e \\
\text { ferrite }\end{array}$ & $\begin{array}{l}{ }^{\circ} \mathrm{C} \\
600^{\circ} \mathrm{C}\end{array}$ \\
\hline
\end{tabular}




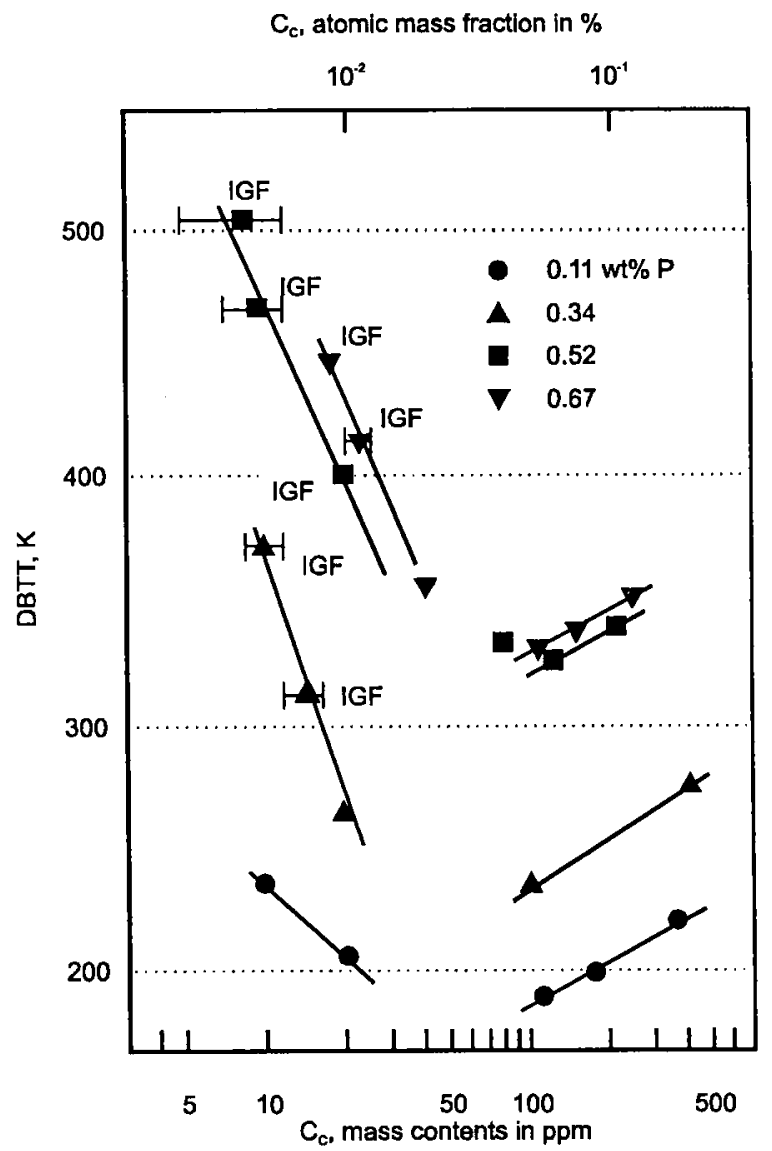

Figure 5. Effect of bulk concentration of $C$ on the ductile-brittle transition temperature (DBTT) of Fe-P alloys [5]. IGF - intergranular fracture

tems which seem to support the intrinsic effect of $C$ in preventing IGF caused by sources other than the segregation of $\mathrm{P}$. One is the effect of $\mathrm{C}$ in the elimination of IGF in pure molybdenum [26]. The other is the result that about an atomic mass fraction of $80 \mathrm{ppm} \mathrm{C} \mathrm{com-}$ pletely prevents IGF in as-quenched specimens of high purity iron, tested at $170 \mathrm{~K}$ under hydrogen charging [27].

A steel with a mass content of about $0.01 \% \mathrm{C}$ can prevent the occurrence of IGF caused by the grain boundary segregation of $\mathrm{P}$ and lower the DBTT in the charpy impact test, figure 5. The increasing DBTT for specimens with $0,02 \% \mathrm{C}$ and more is caused by pearlite nodules [5]. The DBTT is also strongly affected by the $P$ content, an in-

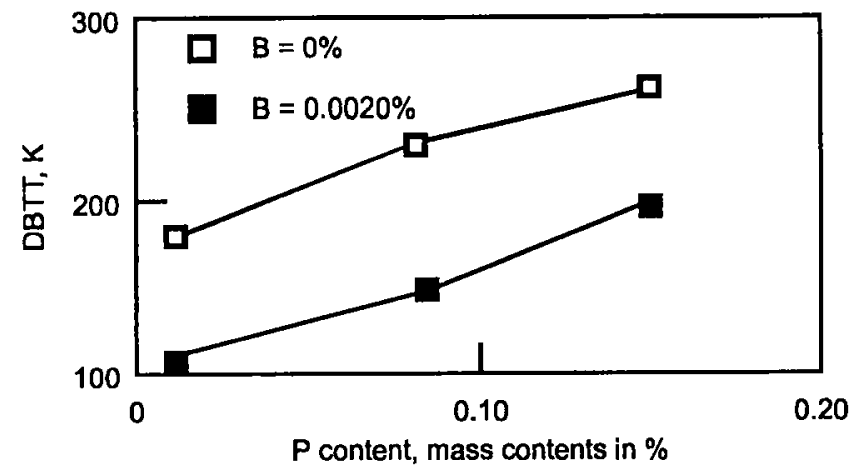

Figure 6. Effect of $B$ addition on the ductile to brittle transition temperature of an ULC steel for different $P$ contents crease of $P$ mass contents from 0.11 to $0.67 \%$ increases the DBTT by around $200 \mathrm{~K}$ when the $\mathrm{C}$ level is $<50 \mathrm{ppm}$ and by around $120 \mathrm{~K}$ when the $\mathrm{Clevel}$ is $100 \mathrm{ppm}$ and above.

Effect of $B$. Boron is generally used to increase the hardenability of some steels. The main disadvantages of adding $B$ to cold formable steels are the corresponding decrease in the $r$ value and the increase in the recrystallization temperature. Since it is a neighbour of carbon in the periodic table, it can be expected that $\mathrm{B}$ has an effect similar to that of $\mathrm{C}$ on the grain boundary cohesion of iron [24]. Because the state of $B$ is difficult to control, owing to its extremeiy low solubility in iron and easy combination with impurities such as $\mathrm{N}, \mathrm{O}$, and $\mathrm{C}$, direct experimental evidence has seldom been found to clarify the mechanism of $B$ acting as an intrinsic effect on the grain boundary cohesion of iron, although a few hypotheses have been proposed $[24 ; 28]$. Nevertheless, this does not preclude the revelation of significant improvement of the resistance to SWE realised by the addition of $\mathrm{B}$. For a high-purity Fe$0.2 \% \mathrm{P}$ alloy, it was found that an addition of $12.5 \mathrm{ppm} \mathrm{B}$ completely prevents the P-induced IGF and lowers the DBTT by about $170 \mathrm{~K}$ in the impact test [14]. Their results on chemical analysis suggests that the segregation of $P$ decreases markedly with the segregation of $B$ while $P$ atoms are replaced by $\mathrm{B}$ atoms at grain boundaries. The suppression of the IGF is attributed principally to the inherent role of $\mathrm{B}$ in increasing the grain boundary cohesion of iron, and secondarily to the decrease in the segregation of $P$ due to the segregation of $B$. The intrinsic strengthening role of $B$ is evidenced in figure 6 showing that an addition of $0.002 \% \mathrm{~B}$ decreases the transition temperature in the cup test by about $80 \mathrm{~K}$ independent of $P$ content [20]. The second effect of $\mathrm{B}$ by displacing $\mathrm{P}$ at grain boundaries is shown in figure 7: $B$ mass contents up to $0.001 \%$ reduce the $P$ segregation, but $B$ addition over $0.001 \%$ has no more effect on the $P$ segregation [20].

Effect of $P$. The grain boundary segregation of phosphorus has been identified to weaken the grain boundary cohesion and act as one of the major factors affecting the susceptibility to SWE [3]. This effect is already reflected in figures 5 and 6 . IGF can also occur in non-IF steels with a high $P$ content due to the segregation of $P$ to grain boundaries [6], but this segregation is easier in IF steels due to no or less solute $\mathrm{C}$ to compete for grain boundary sites. For

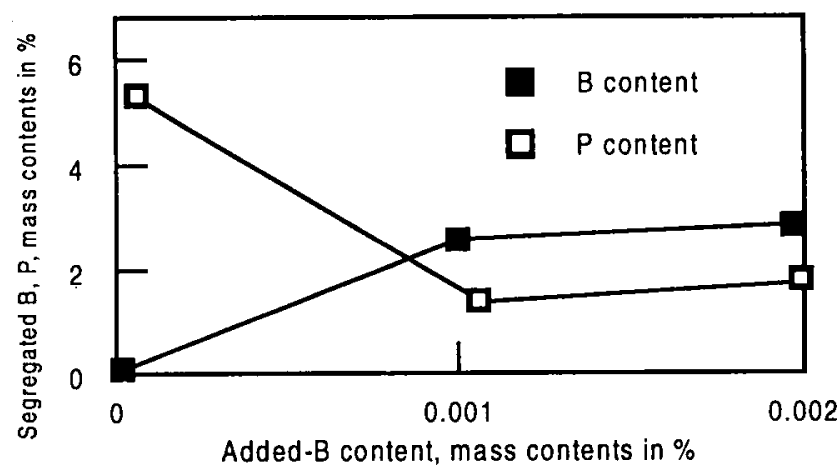

Figure 7. Segregated $P$ and $B$ concentrations at grain boundaries as a function of $\mathrm{B}$ addition $(\mathrm{P}=0.08 \%)$ 
example, the DBTT may become higher than room temperature for a $\mathrm{Ti}$ stabilised steel with just about $0.013 \% \mathrm{P}$ [3]. As an example, figure 8 shows that the percentage of IGF increases with increasing grain boundary $P$ content [6].

The local chemistry near or on the grain boundaries is affected by the processing of the material. For instance, increasing the continuous annealing temperature of cold strip in order to dissolve carbides or annealing in a carburizing atmosphere [29] can dissolve $\mathrm{C}$ and, hence, increase the resistance to SWE, which additionally leads to an increase in mechanical strength associated with bake hardening capability [30]. However, it should be noted that high temperature annealing of fully stabilised IF steels results in a higher resistance to SWE on the condition that an appropriate cooling rate after soaking is applied in order to avoid reprecipitation of the dissolved carbon [31]. Coiling at high temperatures (e.g. $750{ }^{\circ} \mathrm{C}$ ) decreases the amount of solute carbon and hence, increases the DBTT in the SWE test [32], because $C$ tends to react with $\mathrm{Ti}$ to form the precipitation of carbides as the coiling temperature increases. Lowering the coiling temperature of IF steel suppresses full $\mathrm{C}$-precipitation and, hence, improves the toughness of the hot-rolled steel, but the solute $\mathrm{C}$ preserved on the hot-band can precipitate during the annealing process and have a reverse effect.

\section{Mechanical viewpoints}

For the occurrence of IGF in general terms, it is argued that the stress concentration at the tip of a slip band intersecting with a grain boundary may exceed the cohesive strength of the boundary, hence, giving grain boundary fracture [33]. Therefore it is understandable that factors influencing the stress intensification at the tip of a slip band determines whether or not IGF can occur in a specific application, e.g. coarse grains intensify the stress concentration at the tip of a slip band promoting IGF.

For the cup drawing, figure 9 gives the strain distribution as a function of distance from the cup bottom, measured by grid marking, applied to the blanks prior to cup drawing [2]. It is important to notice that the maximum tensile and compressive strains occur near the top of the cup where the IGF is usually found. Since this combination of the maximum tensile and compressive strains causes the grains to elongate severely in the direction parallel to the drawing axis and the tensile stress is applied perpendicular to the elongated grain boundaries as the top of the cup is expanded by a conical ram during the secondary work in the cup test these local conditions promote IGF by a critical weakening of the grain boundaries [2].

For the bend-unbend test, compressive strains are developed around the inner radius during bending. The grain distortion prior to unbending was examined by metallography in order to estimate the strains [9]. It is found that the local strain conditions are similar to a deep drawn cup near the edge $(D R=2.41)$, or even more severe. The results indicate that grains at the outer rim are stretched in the circumferential direction and compressed in the radial direction. In the middle area around the neutral axis, grain

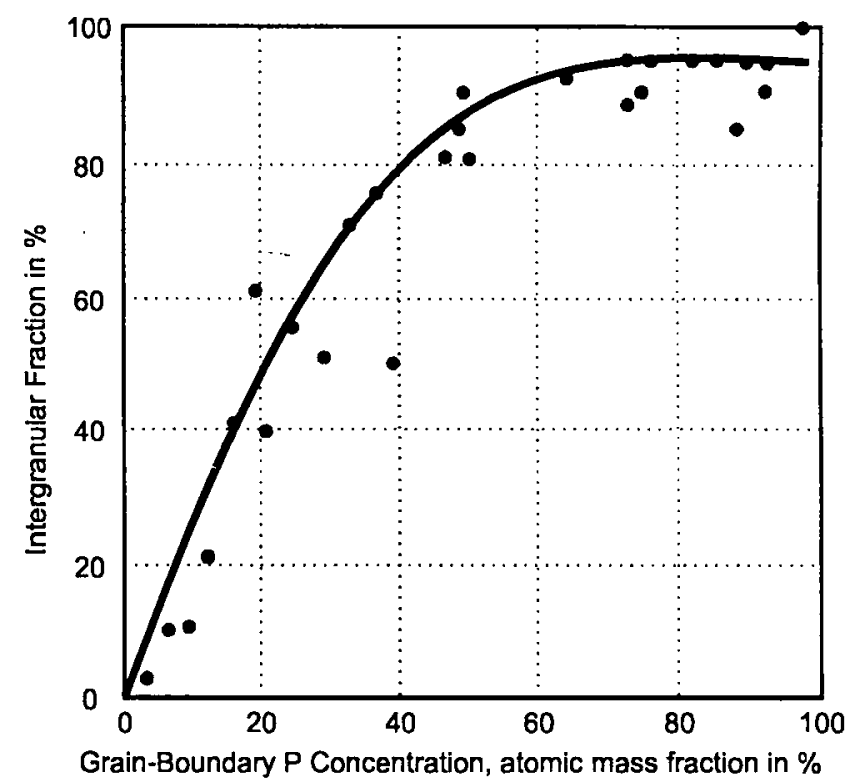

Figure 8. Percentage of IGF as a function of grain boundary $P$ content in Fe-P alloys

distortion is negligible. By contrast, grains in the inner radius region are compressed in the circumferential direction and elongated in the radial direction. It is experimentally confirmed that the DBTT determined by the bendunbend test approximates the one determined by the cup test [9].

Effects of test conditions. Effect of draw ratio (primary strain). The primary strain level and its distribution are mainly determined by the draw ratio, although the sheet thickness and the die entry radius can also affect the strain distribution to some extent. The DBTT increases with increasing the draw ratio, as is shown in figure 10 [32]. Assuming that ductile-brittle transition is a result of counterbalance between yield strength and fracture strength, an increase in the yield strength due to increased draw ratio could reasonably contribute to an elevation of DBTT. Besides, the effect of the circumferential strain, produced

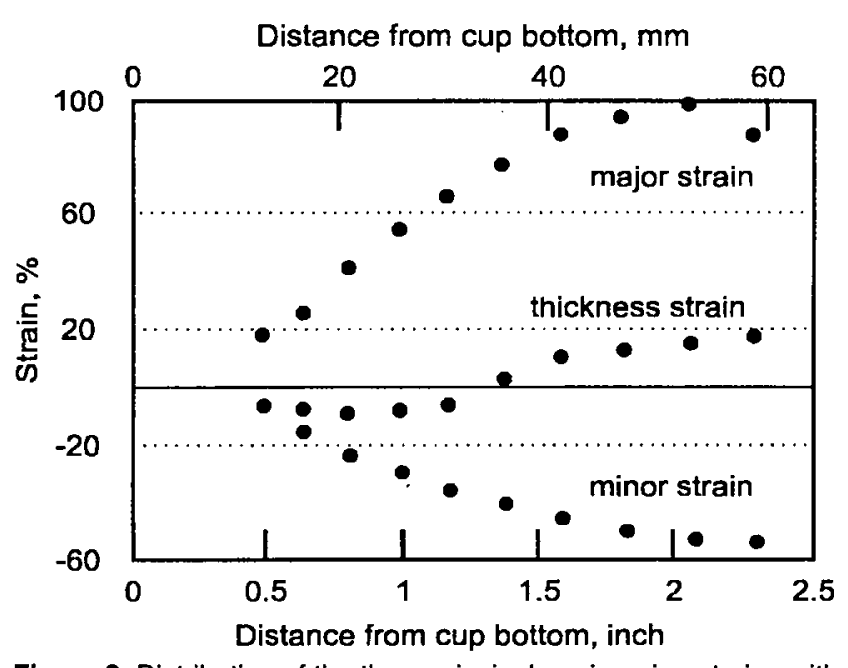

Figure 9. Distribution of the three principal engineering strains with distance from the bottom of a draw cup

draw ratio: 2.41 , thickness of sheet: $0.9 \mathrm{~mm}$, die gap: $1.6 \mathrm{~mm}$, and die radius: $14.3 \mathrm{~mm}$ 


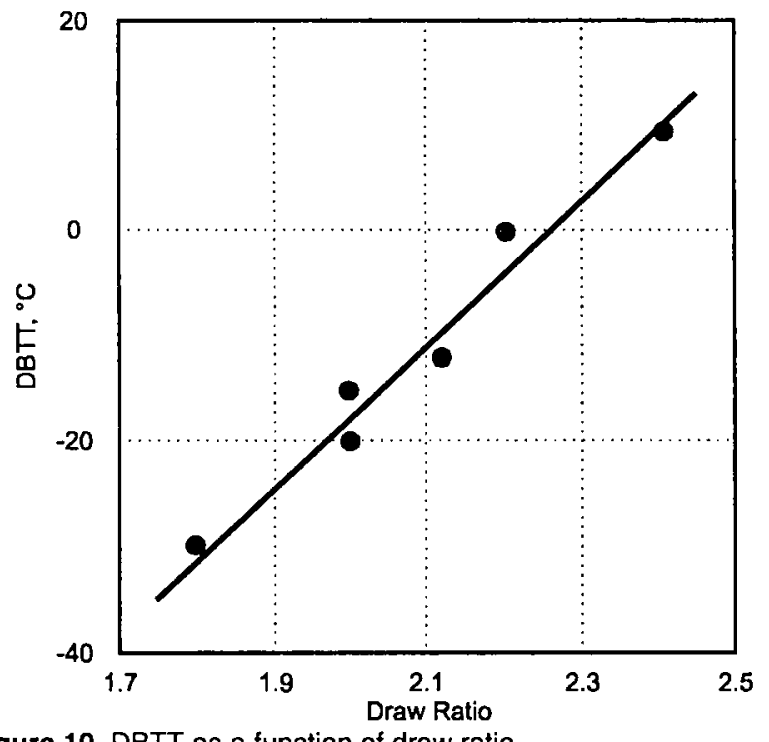

Figure 10. DBTT as a function of draw ratio

due to the release of (the elastic portion of) circumferential stress upon leaving the die during drawing, should also be considered [4], as a higher draw ratio causes higher circumferential stresses and, as a result, higher circumferential strain.

It must be noted that the maximum strains in severely drawn cups are much higher than typical strains in most automotive parts. While in the former major strains up to $99 \%$ and minor strains up to $-55 \%$ are obtained, strains in a door panel (major strain $4 \%$, minor strain $1 \%$ ) or in a quarter panel (major strain 35\%, minor strain $-15 \%$ ) are much smaller. But in floor panels (major strain $62 \%$, minor strain $-49 \%$ ) and especially in oil pans (major strain $100 \%$, minor strain $-50 \%$ ) critical amounts of strain have been reported [32].

Effect of loading rate (strain rate). The DBTT increases with increasing the rate at which the secondary work is applied [2], e.g. a drop-weight cup test gives a higher DBTT than a static cup test. Figure 11 shows that, as the tangential strain rate $\dot{\varphi}$ increases only from 0.04 to $2.6 \mathrm{~s}^{-1}$, the DBTT found in the instrumented conical cup test increases by about $30^{\circ} \mathrm{C}$ for a Ti-stabilised IF steel. Assuming the fore-mentioned ductile-brittle transition argument, this effect is mainly attributed to an increase in yield strength with increasing strain rate. Since the drop height

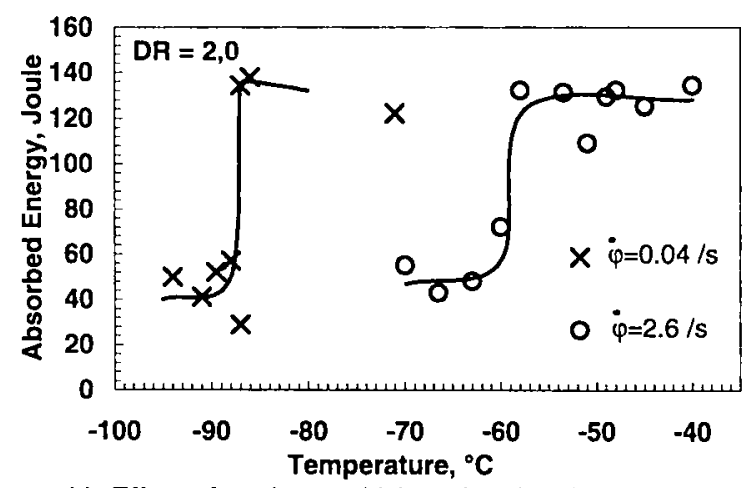

Figure 11. Effect of strain rate $(\dot{\varphi})$ on the absorbed energy $(W)$ vs temperature ( $T$ ) curves determines the velocity for conventional impact cup tests, increasing the drop height increases the DBTT [4].

Effect of cup edge/sheet surface conditions. Trimming the edge of the cup decreases the DBTT under both static and impact test conditions. The presence of flanges in most deep drawing parts decreases the strain level and the stress concentration in critical areas, leading to a decrease in the DBTT [2]. For the bend-unbend test, surface flaws in the form of extrusions are found around the inner radius area, presumably due to the heterogeneous deformation generated in differently oriented grains [9]. These flaws can further facilitate the formation of brittle fracture when the specimen is unbent at an appropriate low temperature. From a viewpoint of fracture mechanics, this type of effect should reasonably be expected.

Effect of tooling dimensions. A decrease in the die profile radius from 13 to $6 \mathrm{~mm}$ causes an elevation in the failure temperature of about $80 \mathrm{~K}$ for a high-P IF steel and is assumed to be attributed to the increased yield strength as the smaller die profile radius hinders the flowing of the steel and thus leads to higher strains [34]. For the bendunbend test, it is found that the DBTT decreases by about 30 degrees with increasing the bend radius from 0 to 0.5 t [9]. As for the tooling condition in the secondary deformation, the cone angle also exhibits an obvious influence on SWE. Because the cone angle affects both the circumferential stress component on the cup and the strain rate at impact, a consistent dependence of the cone angle on SWE has yet to be built up [4].

\section{Discussion}

On the mechanisms. It is concluded by the preceding sections that the SWE in IF steels is mainly caused by grain boundary de-cohesion processes (lack of strengthening elements and/or surplus of embrittling elements). For an easy revelation of the SWE phenomenon as in the cup test, the mechanical conditions have to intensify the secondary deformation process (e.g. drop-weight loading, low temperature, cup expansion with circumferential stress perpendicular to the elongated grain boundaries). These considerations should explain why SWE is scarcely found in a practical secondary forming operation where the straining and/or environmental conditions are usually less severe than in the test for SWE evaluation. Therefore the present evaluation tests actually serve to examine the susceptibility of a steel to SWE. The typical deformation history (heavily deformed at the initial forming stage and intensively strained during the secondary deformation) in the fore-mentioned evaluation tests acts to make the embrittlement more severe through an up-shifting of DBTT but is not an exclusive mechanical condition for the occurrence of the embrittlement. For example, IGF can occur in IF steels under fatigue loading conditions, as in the fatigue crack growth test $[35 ; 36]$.

The grain boundary chemistry plays a key role in affecting the susceptibility of a steel to IGF. This argument has already been confirmed by Hondros and McLean [33], which predicts that most pure metals are close to the bor- 
der-line between ductile and brittle fracture, but more on the ductile side due to the difficulty in satisfying the shearpreventing requirement for IGF. In the presence of decohesion element(s) on grain boundaries, grain boundary cohesion can be reduced by a factor of $\sim 2$ and, hence, the requirement for IGF is readily satisfied for many metals [33].

The important role of grain boundary chemistry is also demonstrated in the occurrence of IGF in many other applications of engineering alloys. Grain boundary segregation of impurity elements such as $\mathrm{P}, \mathrm{S}, \mathrm{Sn}$, and $\mathrm{Sb}$, even with low bulk concentrations (50-200 ppm), is responsible for the occurrence of temper embrittlement, creep cavitation, stress relief cracking, and stress corrosion cracking [37], in which the failure processes all take the path along grain boundaries, despite that contrasting differences in mechanical/environmental conditions exist among these cases. In view of this, the IGF in the case of SWE shares a background common to those found in many other engineering alloys.

On the approaches to SWE. As the IGF found in SWE is common to that found in other grain boundary degrading phenomena in engineering alloys, more fundamental chemical and/or thermodynamical approaches are emphasised in order to understand IGF in general terms. The mechanical tests (e.g. the cup test) show what causes SWE but a fundamental chemical and/or thermodynamic approach should exhibit how it causes IGF and hence SWE. Depending on which aspect of chemical/thermodynamical approaches should be emphasised, a comparison has to be made of the IGF features between the SWE in ULC steels and the embrittlement cases in other engineering alloys. While the segregation of certain elements to grain boundaries is essential for the various IGF processes mentioned above, the different fracture mechanisms depend on different consequences of the segregation process. For the IGF in the case of temper embrittlement, the formation of the embrittling precipitates is necessary for the weakening of grain boundary. In the case of creep failure, the cavitation process is necessitated before any coalescence can possibly occur for the IGF. Under the condition of stress corrosion, the segregation must provide a local electrical potential favourable for the propagation of grain boundary cracking. However, for the IGF of ULC steels such as in SWE, the grain boundary decohesion results from the segregation itself. In other words, it is adequate to consider which element occupies the atom site of grain boundary.

Based on the above analysis, it is concluded that the segregation process has to undergo extensive investigation. The thermodynamical aspects of the segregation are important for getting a fundamental understanding of the process.

Current SWE evaluation tests, e.g. the cup test, detect the susceptibility of a steel to SWE. Due to the non standardised test conditions and inherent inaccurancies these tests can merely provide a relative comparison of SWE susceptibility among materials. Since the deformation history (including primary and secondary forming operations) differs from case to case in practice, it seems impos- sible to use one single parameter (e.g. of strain) to evaluate the phenomenon of SWE. Similar to the concept of equivalent stress in establishing strength theory for multiaxial loading, it might also be worthwhile to investigate the possible existence of a comprehensive parameter describing the (primary + secondary) deformation history.

\section{Concluding remarks}

- The IGF occurring in ULC steels share a common background with the IGF events found in many other applications of engineering alloys. In all of these cases, the segregation of certain elements to grain boundaries plays a crucial role for the decohesion of the boundaries;

- the IGF phenomenon in the case of SWE of ULC steels is mainly detected by the cup test and the bend-unbend test, in which the cup test currently plays a major role;

- the particular strain history intensifies the tendency of IGF through the elevation of the DBTT (ductile to brittle transition temperature);

- the DBTT is increased by high amounts of strain during primary work, by high strain rate, by internal stress and by grain boundary segregation especially of $P$;

- the DBTT is decreased by C and B segregation at the grain boundaries.

\section{Acknowledgement}

The Alexander von Humboldt Foundation (Bonn, Germany) supported the $1^{\text {st }}$ author (D. M. Li) with a research fellowship during which the present study was carried out.

(A 01 437; received: 14. November 1998)

\section{References}

[1] Takechi, H.: ISIJ Intem. 34 (1994), p. 1/8.

[2] Bhat, S. P.; Yan. B.; Chintamani, J. S.; Bloon, T. A.: I\&SM 22 (1995) No. 9, p. 33/42.

[3] Bloom, T. A.; Fosnacht, D. R.; Haezebrouck, D. M.: I\&SM 17 (1990) No. 9, p. 35/41.

[4] Lewis, S. G.; Daniel, S. R.; Parker, J. D.; Llewellyn, D. T.; Sidey: M. P.: I\&SM 25 (1998) No.1, p. 63/73.

[5] Suzıki, S.; Obata, M.; Abiko, K.; Kimura, H.: Trans. ISIJ 25 (1985), p. 62/68.

[6] Erhart, H.; Grabke, H. J.: Met. Sci. 15 (1981), p. 401/08

[7] Yamada, M.: Tokunaga. Y.; Yamamoto, M.: Tetsu-to-Hagané 73 (1987) No. 8, p. $1049 / 56$.

[8] Henning, L. A.: Method to evaluate the susceptibility of sheet steel to secondary work embrittlement, [in:] $33^{\text {rd }}$ MWSP Conf. Proc. ISS, Oct. 1991, St. Louis, Vol. 29, p. 9/13.

[9] Yan, B.; Gupta, I.: Evaluation of bend test for secondary work embrittlement, [in:] 38th MWSP Conf. Proc. ISS, Oct. 1996, Cleveland, Vol. 34, p. 9/13.

[10]Hondros, E. D.; Seah. M. P.: Int. Metall. Rev. 22 (1977), p. 262/301.

[11]Viefhaus, H.: Beugung langșamer Elektronen (LEED)-Analysen von Oberflächenstrukturen, [in:] Oberflächenanalytik in der Metallkunde, [ed.:] Grabke, H.J., DGM, Oberursel, 1983.

[12]Grabke, H. J.: ISIJ Intern. 29 (1989), p. 529/38.

[13]Paju, M.; Grabke, H. J.: steel res. 60 (1989), p. 41/48.

[14]Liu, C. M.; Nagoya, T.; Abiko, K.; Kimura, H.: Metall. Trans. 23A (1992), p. $263 / 69$ 
[15]Neutjens, J.; Mathy, H.; Herman, J. C.: Rev. Mét.-ClT (1997), p. $551 / 61$.

[16]Ohtani, H.; Feng, H. C.; McMahon. C. J.: Mulford, R. A.: Metall. Trans. 7A (1976), p. 87/101.

[17] Schulz, B. J.; McMahon, C. J.: ASTM STP 499 (1972), p. 104/18.

[18]Suzuki, S.; Tanii, S.; Abiko, K.; Kimura, H.: Metall. Trans. 18A (1987), p. $1109 / 15$.

[19]Cianelli, A. K.: Feng, H.C.; Ucisik, A. H.: McMahon, C. J.: Metall. Trans. 8A (1977), p. 1059/61.

[20] Yasuhara. E.: Sakata. K.; Kato, T.; Hashimoto, O.: ISIJ Intem. 34 (1994), p. 99/107.

[21]Cottrell, A. H.: Mater. Sci. Tech. 6 (1990), p. 121/23.

[22] Cottrell, A. H.: Mater. Sci. Tech. 6 (1990), p. 325/29.

[23] Cottrell, A. H.: Mater. Sci. Tech. 6 (1990), p. 807/10.

[24]Seah. M. P.: Acta Metall. 28 (1980), p. 955/62.

[25] Suzuki, S.; Obata, M.; Abiko, K.; Kimura, H.: Scripta Met. 17 (1983). p. 1325/28.

[26]Suzuki. S.; Matsui, H.; Kimura, H.: Mater. Sci. Eng. 47 (1981), p. $209 / 16$.

[27] Kimura, A.; Kimura, H.: J. Japan Inst. Metals 47 (1983), p. 807/13.

[28] Hashimoto, M.; Ishida, Y.; Wakayama, S.; Yamamoto, R.; Dovama, M.; Fujiwara, T.: Acta Metall. 32 (1984), p. 13/20.

[29]Willem, J. F.; Crahay, J.; Leroy, V.: Development of new sheet steels by continuous annealing in reactive atmospheres, [in:] Proc. Intern. Symp. on Modem LC and ULC Sheet Steels for Cold Forming: Processing and Properties, [ed.:] Bleck, W., Verlag Mainz, Aachen, 1998, Vol. 2, p. 533/44.
[30]Ahrens, M.; Bleck, W.:Heat treatment and surface carburizing of sheet steel performed in a new continuous annealing simulator, $11^{\text {th }}$ Congr. Intern. Federation for Heat Treatment and Surface Engg., Florence, Italy, 1998.

[31]Neutjens, J.: Herman, J. C.; Leroy, V.: Hot-band toughness and cold work embrittlement behavior of ultra low carbon steels. [in:] Proc. Intern. Symp. Modem LC and ULC Sheet Steels for Cold Forming: Processing and Properties, [ed.:] Bleck, W., Verlag Mainz, Aachen, 1998, Vol. 2, p. 591/602.

[32] Yan. B.; Gupta l.: Secondary work embrittlement of interstitial free steels, [in:] Proc. Intern. Symp. Modern LC and ULC Sheet Steels for Cold Forming: Processing and Properties, [ed.:] Bleck, W., Verlag Mainz, Aachen, 1998, Vol. 2, p. $249 / 63$.

[33]Hondros, E. D.; Mclean, D.: Grain boundary fragility, [in:] Grain Boundary Structure and Properties, [eds.:] Chardwick, G. A. and Smith, D. A., Academic Press, London, 1976, p. 353/81.

[34]Lewis, S. G.; Daniel, S. R.: Sidey, M. P.; Parker, J. D.: Assessment of the susceptibility to cold work embrittlement with relevance to the automotive industry, [in:] Proc. Intern. Symp. Modern LC and ULC Sheet Steels for Cold Forming: Processing and Properties, [ed.:] Bleck, W., Verlag Mainz, Aachen, 1998, Vol. 2, p. 603/14.

[35]Putatunda, S. K.; Krohn. R.; Sengupta, A.; Singh, J.; Davies, R. G.: Fatigue crack growth behavior of high strength interstitial free (IF) steels, Intern. Symp. Low-carbon Steels for the 90's, [eds.:] Asfajani, R. and Tither, G., TMS, 1993, p. 453/64.

[36] Kocik, R.: et al.: Mat.-wiss u. Werkstoffech. 28 (1997). p. $287 / 92$.

[37]Misra, R.D.K.; Ram Rao, P.: Mater. Sci. Tech. 13 (1997) No. 4, p. $277 / 88$. 